\title{
A Virtual Body Politic on \#Gaza: The Mobilization of Information Patterns
}

\author{
LAILA SHEREEN SAKR, ${ }^{1}$ University of Southern California
}

\begin{abstract}
From Walter Benjamin and Dziga Vertov to Instagram and machine vision: new strategies of seeing and representation in modern and software societies constantly emerge and reshape our field of phenomenological, affective, and discursive vision. Social media's use of images and representations of the body, within the highly securitized and militarized networks and landscapes that we traverse, focuses attention on the body as a site of contested political control and capitalist consumerism. This study of a virtual body politic provides a close reading of two data visualizations from Twitter conversations on Egypt in 2011 and Gaza in 2014 in order to analyze the mobilization of information patterns over time. These visualizations of Internet data are not about claims about material bodies or the intentions of communicators, but traces of an embodied moment of intentional use of digital media. Every data point has an embodied analogue at some moment. And tweets have a very particular (historically specific, geo-specific) moment of origin that is exceedingly tangled with materials bodies. My aim here is to determine what the emerging patterns tell us about a virtual body politic.
\end{abstract}

\section{KEYWORDS}

Gaza; Egypt; Twitter; Social Media; Data Visualization; Mosaic; Virtuality; Body Politic; Network Visualization; Media Praxis; Petabyte Age

\footnotetext{
${ }^{1}$ Laila Shereen Sakr also publishes her work under her moniker, VJ Um Amel: http://vjumamel.com. This research is made possible by a grant from The Arab Council on Social Sciences.
} 


\section{Introducing the Virtual Body Politic}

"What is the next big idea in language, history and the arts? Data."

New York Times, November 16, 2010

The joint availability of massive social and cultural data sets (including social media and digitized cultural artifacts) make possible fundamentally new paradigms for the study of social and cultural activities and histories. Access to information and justice in the Arab world has been reframed through open source industry models, social media platforms, and Arabic software localization. But these changes have yet to be meaningfully analyzed or even accounted for by scholars studying either social media or the societies in question.

The scope of my research is in fact one layer removed from the individuals and communities themselves. In this inquiry, I examine various assemblages of people in the virtual world through their words, their sharing, and their posts online. By examining traces that people leave online through posts, tweets, retweeting, sharing, I formulate and study various assemblages of people and their ideas - creating alternative geographies of movement and new spatialities of information patterns. The question is not to identify "who" the people are ontologically, but how they form networks of solidarity, and around production of knowledge, on the Internet. This project studies the flows of cultural production and consumption in real-time, so that the assemblages are in constant flux.

By juxtaposing data visualizations using social media from the summer months of the 2011 Egyptian revolution to the attack on Gaza in the summer of 2014, my goal is to understand the hermeneutics (text and context) of digital knowledge produced from social unrest and citizen action as it flows among transnational actors from the earlier events in Egypt to a violent war against Gaza three years later. These two particular events occurred over the summer, and received similar levels of international attention. Both the Egyptian revolution and the attack on Gaza had regional implications, and the social media conversation occurred in many languages. Another reason for comparing these two events is to understand how various data visualization techniques can shed light on unique information patterns and the mobilization of various information patterns.

This brings me to my point about a virtual body politic. I argue that it is the actual material bodies that are writing the information patterns we read on social media, if you will. And with social media, for the first time, we are seeing media being circumscribed by its millions and millions of users rather than one state-run apparatus like a newspaper or television network. These authors have become a plethora of different bodies - big ones, black ones, brown ones, Muslim ones, Atheist ones, queer ones, and all the variations. It is this largeness ${ }^{2}$ in daily political movement and operations that is defining the social media production of knowledge. It is revolutionary.

\footnotetext{
${ }^{2}$ Reference to excerpt from Walt Whitman's Leaves of Grass: "Do I contradict myself?/ Very well then, I contradict myself./ I am large. I contain multitudes.”
} 
Another example of solidarity networks operating across differences is this photograph of a young girl holding a sign that reads "Ferguson with love from Palestine." On the night of the no indictment verdict of officer Darren Wilson in Ferguson, Missouri on November 24, 2014, this photograph was the third most tweeted image among 650,000 tweets collected on \#Ferguson.
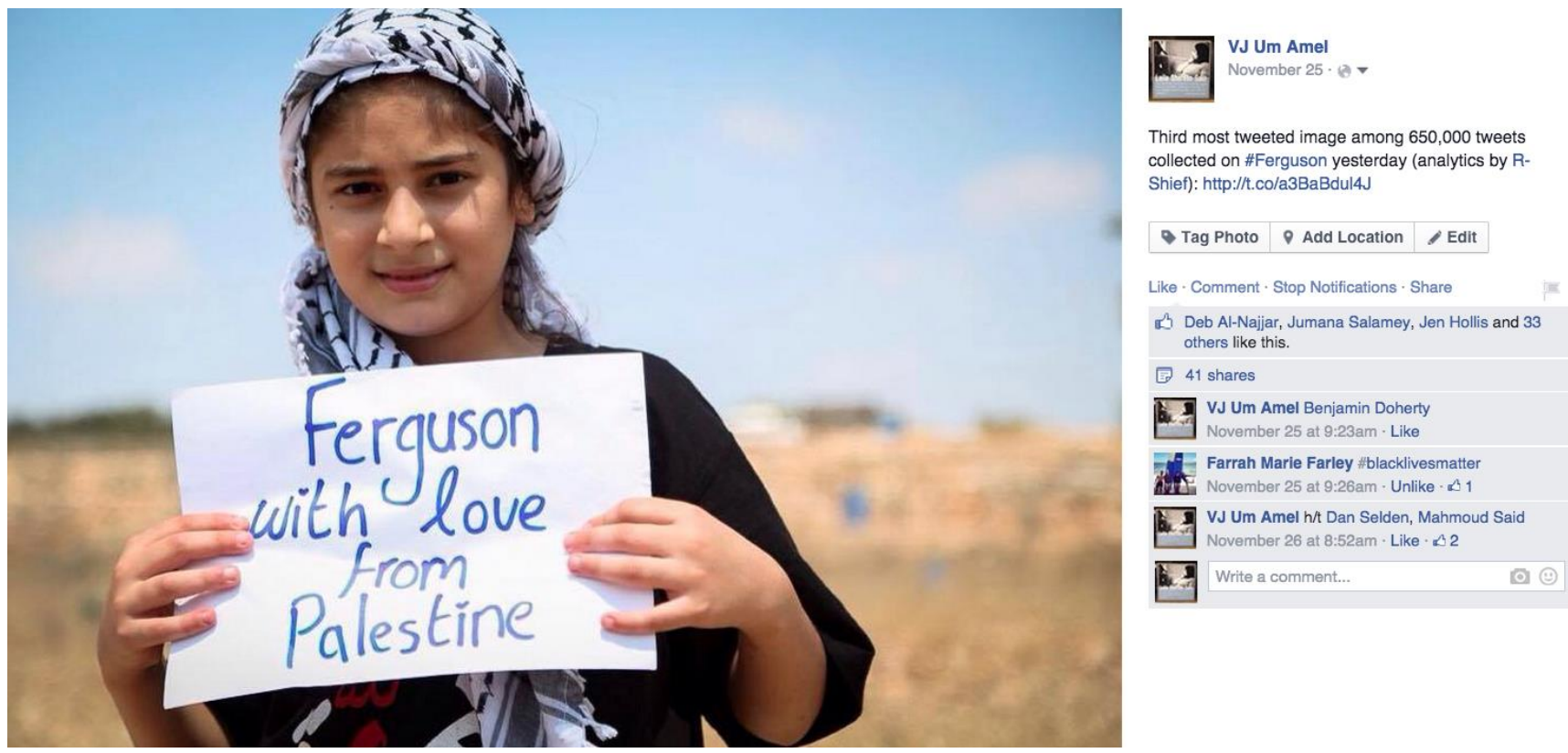

Fig. 1. Image ranking analytics from R-Shief.org.

A difference between the body politic and the virtual body politic is that the former is an abstraction of a group of people governed by one authority. More importantly, the latter is that abstraction of people who exchange ideas publicly online about the governance of an authority through visual representations of bodies as a site of political control. More than the accumulation of data, in this discussion I am concerned with public sharing among global witnesses - a virtual body politic. The notion of witnessing culture, while science gives us a means to speak about the implications, is powerful. In some respects, and not incidental to the virtual body politic, the sharing of tweets creates an immediate publicity ${ }^{3}$, which really broadens who can be a witness, who can be counted as a witness. This article presents a media-enhanced method of scholarship, a media praxis, to analyze and demonstrate the negotiation between the materiality (the analogue) and information patterns (the data points). In this context, virtuality itself is a friction point between material bodies in political operation and information patterns.

\footnotetext{
3 "A revolutionary age is an age of action; ours is the age of advertisement and publicity. Nothing ever happens but there is immediate publicity everywhere" (Kierkegaard 1962).
} 


\section{Cultural Research in the Petabyte Age}

In his article, "Art in the Age of Mechanical Reproduction," Walter Benjamin concluded that when art loses the magical and ritual purpose from its own creation and is reproduced, it negotiates a political dimension. At the end of his article, Benjamin provides a Marxist analysis by intertwining the role of reproduced art reaching "the masses" and the Fascist "attempt to organize the newly created proletarian masses without affecting the property structure... [and by] giving these masses not their right, but instead a chance to express themselves" (Benjamin 2008, 3).

Yet, in the era of mechanical reproduction, we have moved to a theology of art for art's sake, heightened in the late nineteenth century by artists like Oscar Wilde. Benjamin uses the terms "cult of art/cult of beauty" to depict a new group of recipients of the art, a wide audience. This point is also central to his argument; also the way he negotiated the word, "aura." Benjamin articulated the aura of a piece of art to emanate from its own authenticity, as is bound to time, space, and circumstance of its birth. If the emphasis of the art has shifted to it being relevant to a cult, a mass audience, then it would be that audience (not the artist) who gives a piece its authenticity. I suggest that the aura of a piece of art in the age of mechanical reproduction is found in its relationship/play/interaction with its audience — and this is political.

In his work on contemporary Arab music during the 2011 revolutions, Mark LeVine argues the return of Benjamin's notion of "aura" (LeVine 2012). From an Adornian perspective on the globalized consumer society, he argues that, within the context of revolution, music played an important role "to awaken people from their ideological slumbers." I would even extend LeVine's argument and add that social media allows its authors to express an emotional register that exhibits and performs in a way similar to Benjamin's aura.

Nearly a hundred years have passed since Benjamin wrote his oeuvre, and we have reached a situation nearly the opposite to the one in which Benjamin was theorizing. In our world, the Petabyte Age, media is freely produced and endlessly circulated without explicit commodification. In 2008, WIRED magazine recounted the history of digital computation (2008):

Sixty years ago, digital computers made information readable. Twenty years ago, the Internet made it reachable. Ten years ago, the first search engine crawlers made it a single database. Now Google and like-minded companies are sifting through the most measured age in history, treating this massive corpus as a laboratory of the human condition. Welcome to the Petabyte Age. The Petabyte Age is different because more is different. As we moved along that progression, we went from the folder analogy to the file cabinet analogy to the library analogy toand, at petabytes we ran out of organizational analogies. At the petabyte scale, information is not a matter of three- and four- 
dimensional taxonomy and order but of dimensionally agnostic statistics (Anderson 2008).

The Petabyte Age calls for an entirely different approach to cultural research. This approach requires us to stop thinking about data as something that can be visualized in its totality. Instead, it requires us to understand the data mathematically first, and only later can we begin to ask questions about context: people/place/time of data production.

When researching social media, for example, parameters such as time stamping or geolocation offer pointers to the context of initial production, but in creating the database, the virtual bits are dramatically decontextualized. The database creation process simply cannot easily record the salient conditions of the production of the elements. Walter Benjamin might say that the aura of the data is unrecordable.

In order to produce a database, bits of information are algorithmically processed and fitted into a database structure that enables the data to be "read." This initial computational processing does not do much to account for the context of the production of the original information. Basically, it might tell us about the patterns of information but very little about the meaning of this information.

The methodologies I used to produce the interactive data visualizations for this research project include hashtag (\#) analysis, topic modeling using network graphs, and image analysis. Network graphs connect a series of dots using lines. You can graph various entities such as relations among people. I use this type of graph to conduct topic modeling, a method of producing analytics on topics by keywords. I also did hashtag analysis that required some semantic analysis. In order to analyze the images, I experimented with creating different mosaics of profile pictures. These image mosaics are a type of cultural analytics - an approach to data visualization that situates visual imagery as a site of political control and capitalist consumerism. The most recent mosaic I've created is on the 2014 attack on Gaza, through the display of a mosaic of images tweeted using five separate hashtags. Before discussing the Gaza mosaic, however, I will first turn to an earlier mosaic; based on tweets made during the Egyptian revolution in 2011.

\section{The Bare \#Egypt Tweets in 2011}

In his article, "The Arab revolutions; the emergence of a new political subjectivity," Sari Hanafi (2012) argues that the Arab youth feel that they have become a Homo sacer, in the sense of Agamben, which means that this was the revolt of 'bare lives'; that is, of defenseless hungry bodies that the regime had stripped of political identity and of the right to belong to such groups as the Islamic Renaissance Movement 'al-Nahda', the Tunisian Communist Labor Party, and the Muslim brotherhood. In Homo Sacer, Agamben connects the problem of pure possibility, potentiality, and power with the problem of political and social ethics in a context where the latter has lost its previous religious, metaphysical, and cultural grounding. Agamben probes with great breadth, 


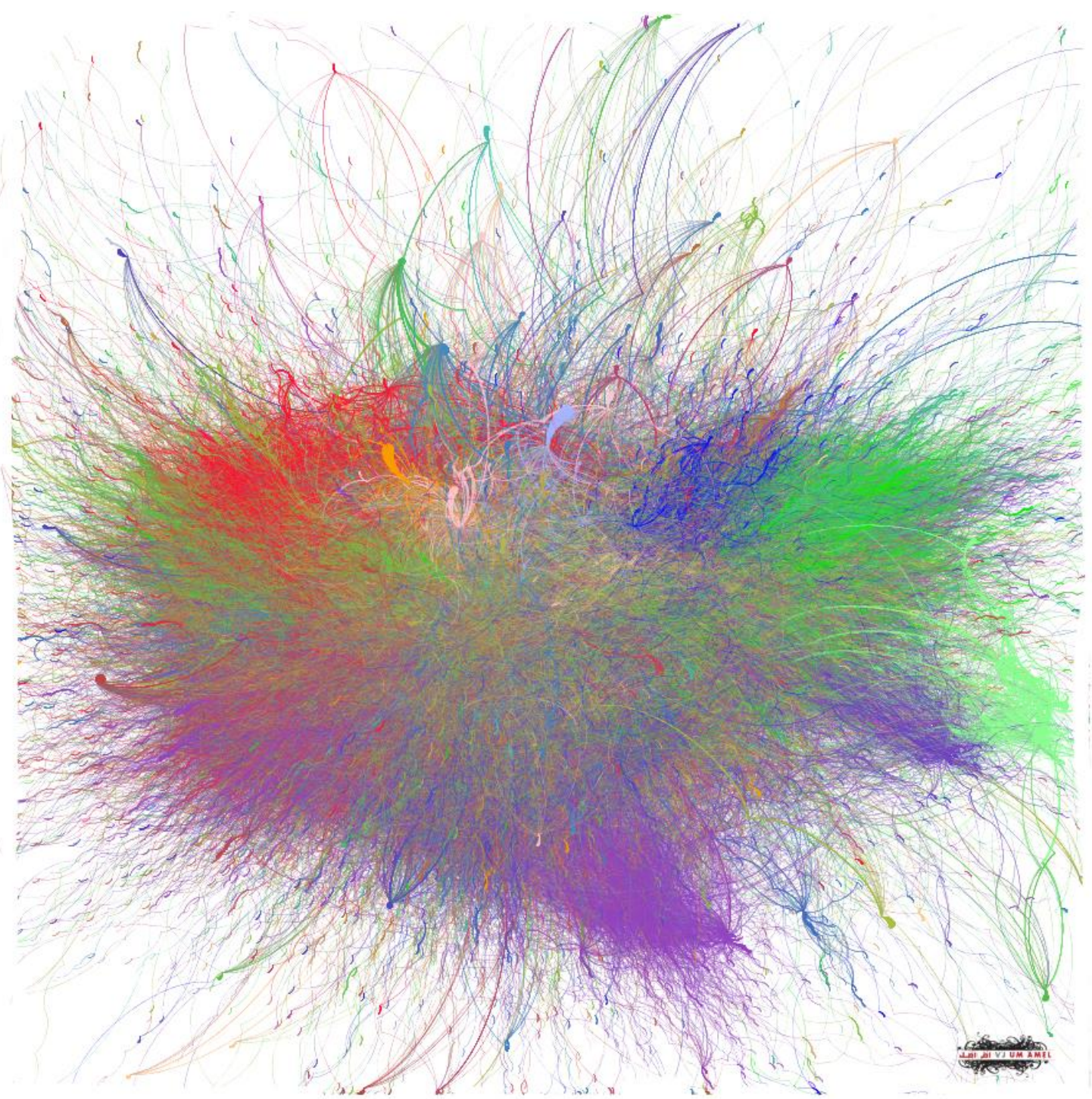

Figure 2. A network visualization by language of half-a-million tweets on \#Egypt in July 2011. English and Arabic make up the vast majority of the twitter traffic. The breakdown is 59\% Arabic (Green), 30\% English (Blue), 2.25\% Hindi (Gold), 1.6\% French (Red), 0.7\% Urdu (Purple) and 0.6\% Finnish. The remainder (Farsi, Spanish, Italian, Portuguese) is less than 0.5\%. By VJ Um Amel, 2011. Analytics from R-Shief.org.

intensity, and acuteness the covert or implicit presence of an idea of biopolitics in the history of traditional political theory.

Taking his cue from Agamben's state of exception, Hanafi constructs a theory of selfreflexive individuality in the context of the change of regime and revolution in the Arab world. His analysis explores the "new political subjectivity ushered in by these revolutions, in the specific form of individuality", or what he terms "reflexive individualism". "This individualism, which is different from the neoliberal concept, is not a straightforward one predicated on anti-patriarchal authority, anti-tribe, anti-community, or anti-political party sentiments. The political subjectivity of the individuals who have 
taken part is formed and shaped both within and across the shadowy edges of political institutions and their production of legitimacy and knowledge" (Hanafi 2012).

The political movements that took place in Egypt in 2011 involved millions and millions of individual participants. My attempt to capture this "reflexive individuality" materialized in this highly abstract network visualization of over a half a million tweets of \#Egypt over the month of July 2011. It is a metonymic stand-in for the virtual body politic itself.

The network drawing in Fig.2 (above) represents a sensory experience of the immensity of online media - the network has become so complex, big, and alive. My intent is to offer a new perspective on the microcosms within macrocosms of this world, somewhat unfinished, and unknowable - to bring these complex representations of movements of millions and billions of people with many leaders together in a way that allows you to experience through the senses what nobody logically organizes in their human head.

In 2011, it was Bouazizi's act of protest-suicide that created a pattern of resistance whose effectiveness was achieved at the moment of the body's self-immolation, and the posters and theatrical chants, music, comedy, and sarcasm that unfolded in Tunisia caused a domino effect in other Arab countries, starting in Egypt. In this setting, the revolutionary youth are educated individuals who came together in places like Tahrir Square and the Twitter sphere in acts of solidarity mediated in front of global witnesses. Mohamed Bouazizi, who died by committing suicide, became an actor who deliberately sacrificed himself, and by that act, inverted the relationship with the sovereign authority.

In 2014, the Palestinian resistance in Gaza also challenged the sovereign authority that sought to turn them into humiliated subjects who could be killed without any recognition, i.e. death without value. The devastating and disproportionate attack on Gaza produced a different relationship between the Palestinian body politic and the occupying state.

\section{\#GazaUnderAttack}

The most underlying difference to consider when studying the violent attacks on the people of Gaza in 2014 is that they have been under siege in this manner since 2006 with cuts from water and power supplies and direct military attack from the state of Israel. As of 2014, there are hundreds of thousands of children under the age of ten in Gaza who have lived through three wars in their short lifetimes. The accumulation over the years of young bodies under siege has become obscene.

I argue that the exhibition of young, dead Palestinian bodies on display on social media felt not just obscene, but pornographic. The excess of violence, the excess of the images, was pornographic. "Pornography," Robert Jensen writes, "is what the end of the world looks like" (Jensen in Hedges 2015). We are blinded by self-destructive fantasy. An array of amusements and spectacles, including TV "reality" shows, huge sporting events, social 
media, porn (which earns at least twice what Hollywood movies generate), alluring luxury products, drugs, alcohol, and magical Jesus offer enticing exit doors from reality.

I created \#Gaza Audio-Visual Narrative by a Cyborg: Images Tweeted by Hashtag as an interactive, audio-visual narrative using five sets of posts from Twitter on \#Gaza that were gathered and analysed by R-Shief. It includes an interactive mosaic of the surveillance image that went viral of the boys killed on a beach, along with computerized sound files of the tweets and an organized gallery of the images most tweeted. The mosaic is comprised of more than a thousand images posted on Twitter within an hour on 26 July 2014.

Simply comparing the imagery of the very real public sphere of Tahrir during the revolution and subsequent protests when the square festooned with huge posters of gruesome images, from those of the martyred to the pornographic violent images of broken young Palestinian bodies, brings insight. How does the Tahrir experience-in human scale with 20-feet high images-compare with the smaller scale of the phone or computer?

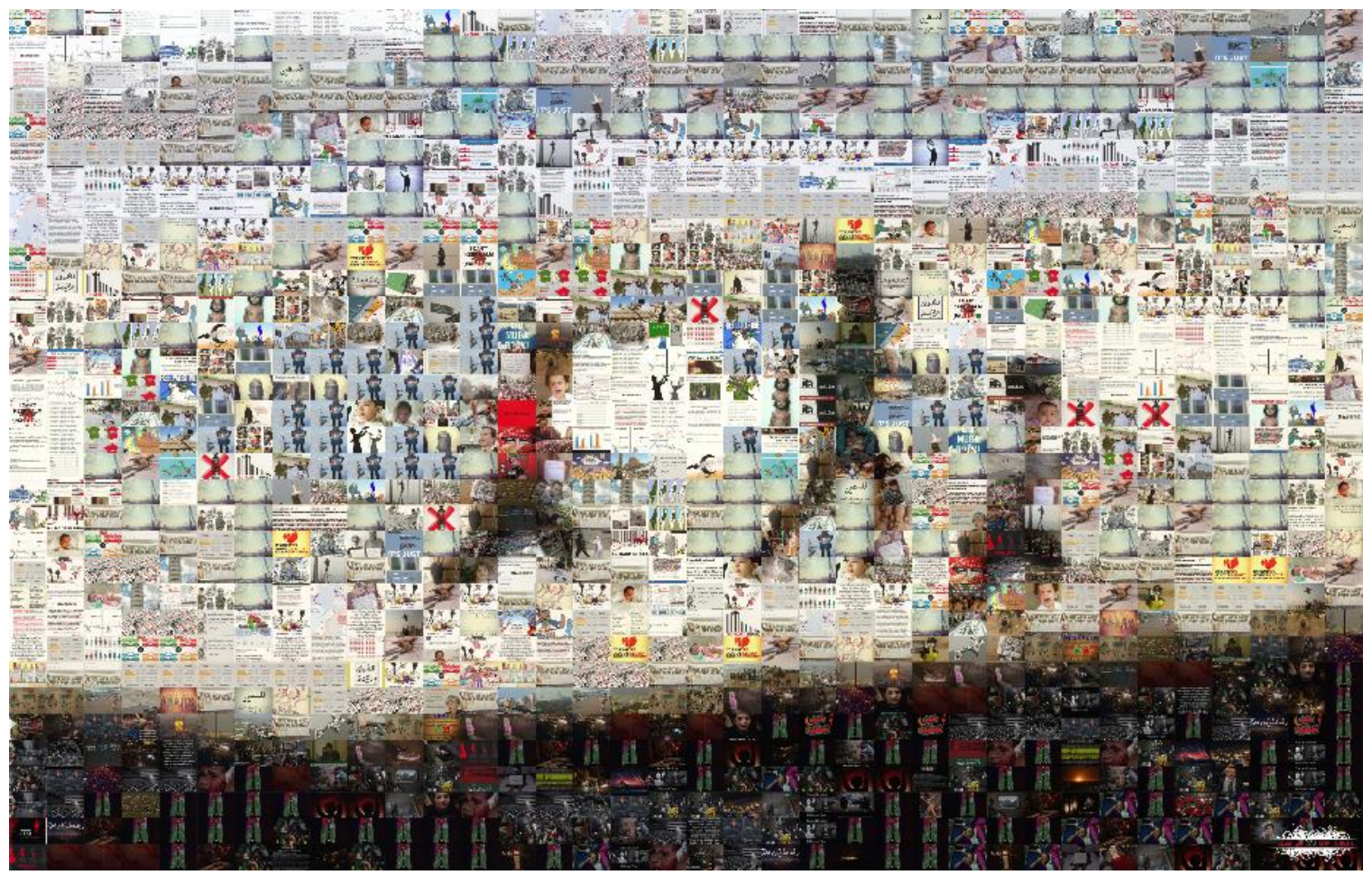

Figure 3. VJ Um Amel, \#Gaza Audio-Visual Narrative by a Cyborg: Images Tweeted by Hashtag (August 2013, screenshot of interactive audio-visual mosaic).

The design process I used to make this piece combines a method of cultural analytics with a world-building approach to narrative, displayed through a web interface. This media praxis draws upon the works of Lev Manovich and Jeremy Douglass in cultural 
analytics. However, rather than using formal elements like color or hue to determine the procedural form of the image, my process involves pulling culturally significant content and prioritizing images that are most popular in my representation of social media on Gaza by hashtag. This is determined through analysing trends on Twitter, Facebook, Instagram, YouTube, and other websites.

By clicking on the \#Gaza Audio-Visual Narrative by a Cyborg interface (please do so), the user is able to enter this world of images and audio tweets. ${ }^{4}$ The immersive experience is meant to make you feel the bodies bloodied and maimed, bombed and broken, in photographs on social media in the hundreds of thousands. On the homepage is an interactive mosaic with a mix of images parsed from sets of tweets by five hashtags: \#GazaUnderAttack, \#Gaza, \#48KMarch, \#PalestineResists, and \#ProtectiveEdge. As you hover over the mosaic, the images enlarge. When you click on the hashtags on the menu at the top, you get a traditional gallery display of the images tweeted with that hashtag only. This function allows users to compare mobilizations of information patterns.

\section{The Hashtags}

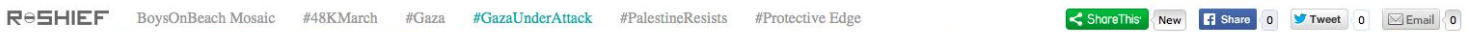

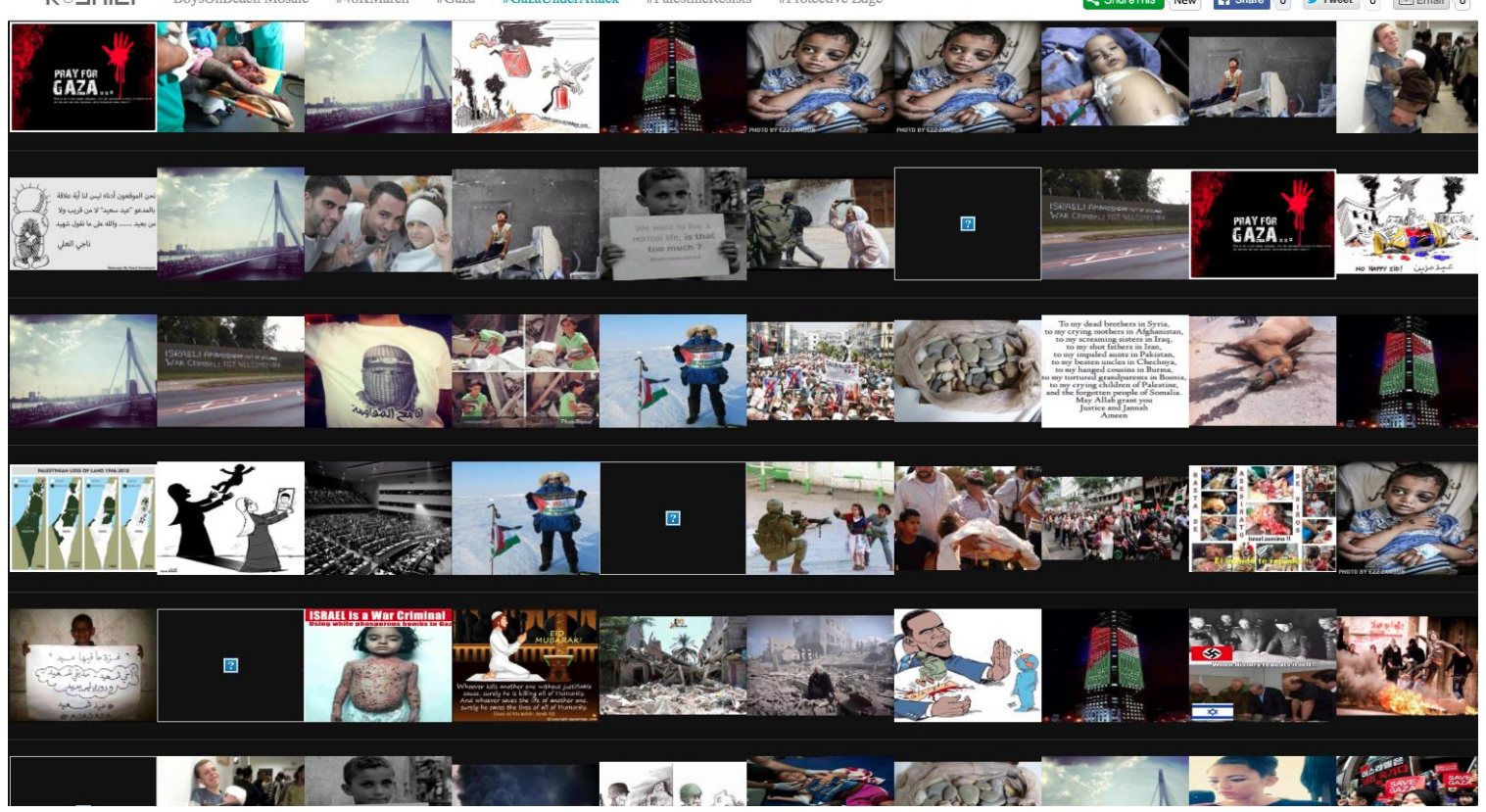

Figure 4. Screenshot of interface provides a gallery of images with the hashtag \#GazaUnderAttack. Analytics from R-Shief.org

\footnotetext{
${ }^{4}$ VJ Um Amel, http://vjumamel.com/portfolio/gaza-audio-visual-narrative-by-a-cyborg-images-tweeted-byhashtag/ (accessed 15 September 2014).
} 
By comparing various sets of hashtags, semantic differences emerge among different online communities. In covering most events, there are often several hashtags circulating. One will represent the name of the person, place, or event, such as \#Egypt or \#Gaza. And then there are the more creative hashtags that represent a political position or movement in a particular struggle; in this instance, \#GazaUnderAttack (see Figure 4) represented the voice of the majority of tweets on Gaza, even more than \#Gaza tags. More than half of the people tweeting on the subject saw the people in Gaza as victims. The fewest tweets came from the hashtag \#Palestine Resists, used by activists, and \#ProtectiveEdge (see Figure 5), which is the Israeli name for the offensive against Gaza that summer.

According to literary critic, Katherine Hayles, "the characteristic of virtuality is to exist in such a way that it is actualized by being differentiated and is forced to differentiate itself, to create its lines of differentiation in order to be actualized" (Hayles 1999, 27). The virtual cannot become-actual without differentiating itself in the process. In a way, the virtual will always miss the mark of actuality through this differential; it must toggle undecidedly between presence and pattern, "materiality on the one hand, information on the other," as Hayles asserts. This raises the question: is the virtual even a useful category of hermenteutics anymore? Or are our lives so integrated with the various experiences that even conceiving of the physical and the virtual as distinct becomes empirically and/or phenomenologically misguided?

There are data files, programs that call and process the files, hardware functionalities that interpret or compile the programs, and so on. It takes all of these to produce the electronic text. Omit any one of them, and the text literally cannot be produced. For this reason, it would be more accurate to call an electronic text a process rather than an object (Hayles 2003).

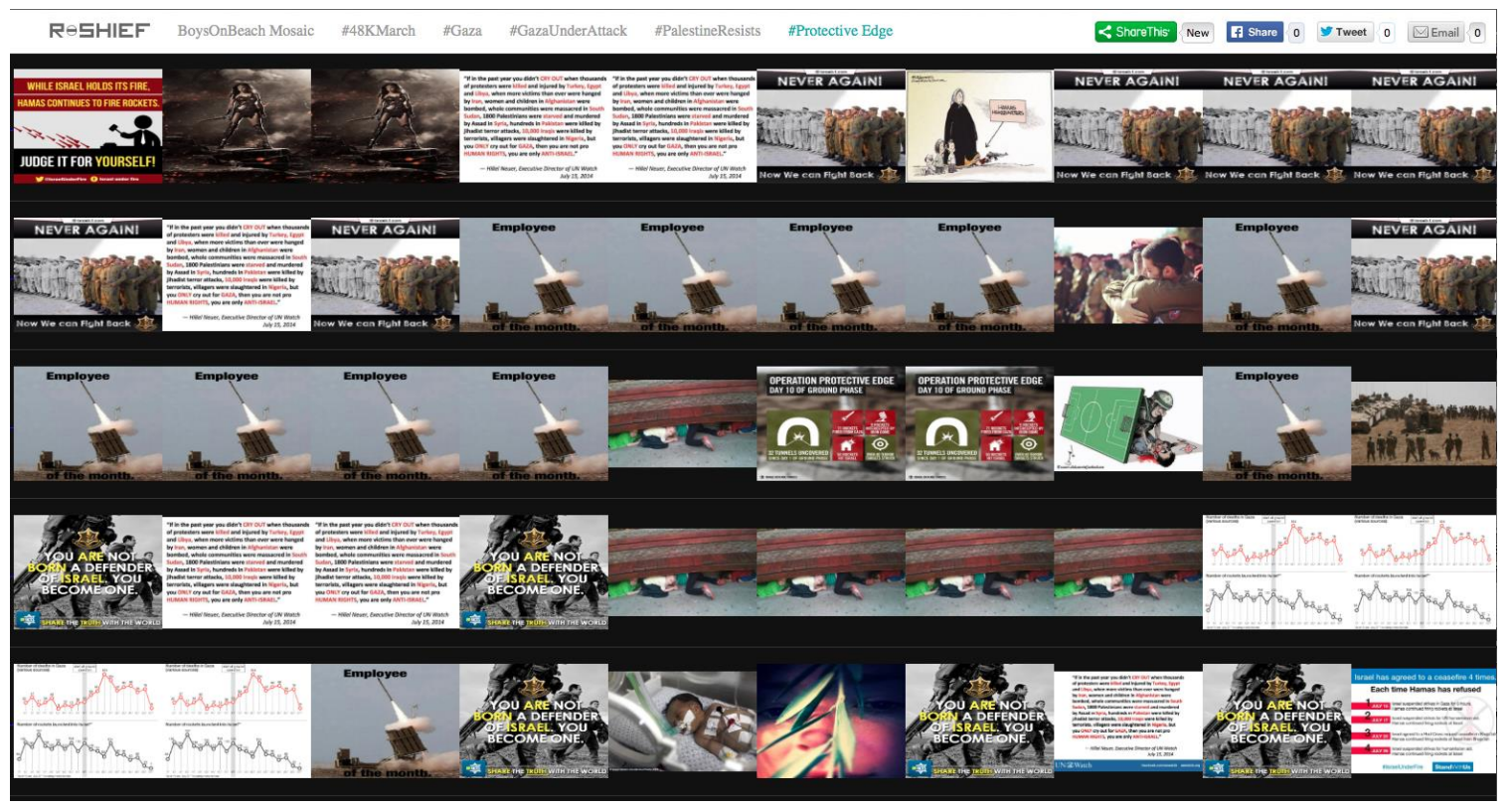

Figure 5. Screenshot of interface provides a gallery of images with the hashtag \#ProtectiveEdge. Analytics from R-Shief.org. 
Even these other entities - files, programs, hardware functionalities that are "literally" necessary for the production of the electronic text - seem to be working in the service of a familiar "literary" textual persistence. Are the tweets here seen as a process or the authorized result of a process? Finally, what about when text as "transitory image" can be mobilized through such innovations as dynamic typography, and where words function both as verbal signifiers and visual images whose kinetic qualities also convey meaning? Are these dual-aspect "word-images" functioning, for the critic or reader, in time? Whose real time? The author's time? The reader's time? Are they processes or have they just acquired (new) qualities?

I do want to argue, in agreement with Hayles, that text is process, but in order to allow code to comment on the writing machine, we need to elaborate a stronger statement of this argument, one that is less fixated on a layered, flickering structure that imitates persistent text, or on a text - persistent in this sense - that is able to "acquire" paratextual dynamics. Instead, we need to recognize a textuality that is itself a dynamic because it contains, conceals, and runs on code, because it exists only as a durational, transliteral process.

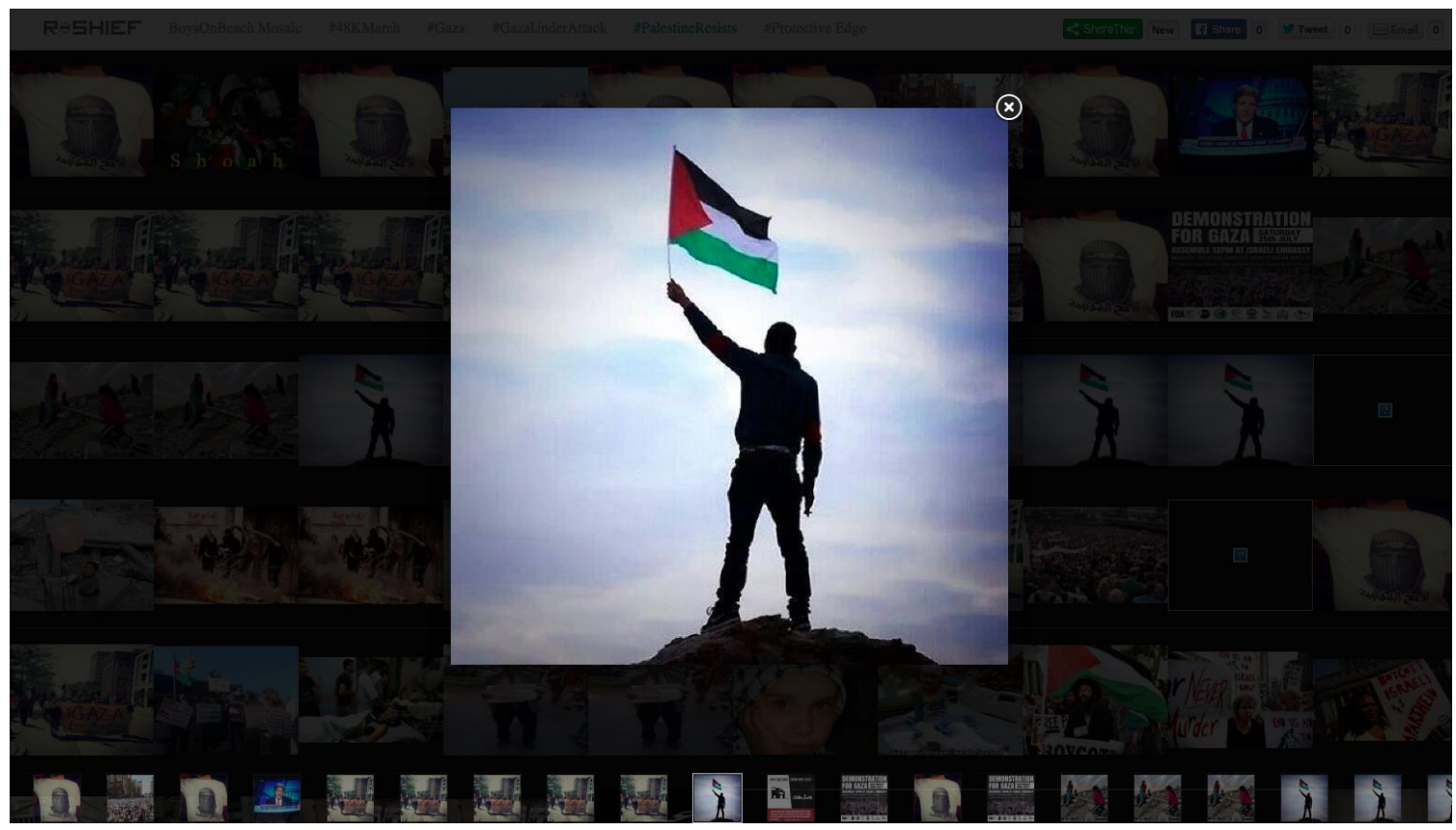

Figure 6. The interactive visualization provides multiple ways to view the tweeted images: in the mosaic, hovering over the mosaic, in a gallery by hashtag, and in this close-up view. Analytics from R-Shief.org

\section{Conclusion}

Hayles defines virtuality as a negotiation between materiality and information patterns that are generated in the virtual world (Hayles 1999). Thus, virtuality itself is comprised of the words in the ideas expressed on social media, not the people themselves. Looking 
at social media content through a virtual lens requires a focus on a different kind of analytics - on information patterns and flows.

Hayles demonstrates "how information lost its body" in order that we might better know how to keep disembodiment from being written once again into dominant concepts of subjectivity. She explains that electronic textuality involves multiple senses utilizing signifying components that allow us to see images as elements of narrative (Hayles 2003, 44).

This research engages a set of methodologies that emerge at the intersection of both cultural and technical analytics. The first objective is to provide some historical context for the growing interest in the analytic properties of social media content. I argue that the stock of 'primary data' is important, but not determinant in creating nuanced cultural analyses. This research considers the work of data visualizations, especially in relationship to the stock of primary data (actual tweets, status posts, etc.). The second objective is to argue for the importance of paying attention to the specific language of the stock of primary 'social media' data. In my work, I focus specifically on the use of Arabic online. This is absolutely critical for a number of reasons. Of course, there is the cultural moment of what has been called 'The Arab Spring.' But most analyses of this so-called 'social media' revolution had not taken into consideration the analysis of the meaning of actual Arabic language use. After harvesting and analyzing Twitter posts for more than five years $(2009$ - 2015), I became aware that the use of Arabic language online was steadily rising. For example in one month alone (April 2012), more than 80 per cent of the tweets that used the English-language hashtags \#Tahrir and \#Jan 25 were written in Arabic. More than 95 per cent of tweets using related Arabic hashtags were written in Arabic. Hence, by presenting this work, I hope we come closer to identifying and addressing the gaps in the visual and textual analysis of digital information on the Middle East and North Africa.

This media praxis methodology interrogates new modes of knowledge production as reflexivity, transdisciplinarity, and heterogeneity in the age of "big data". Through critique of database narrative and the computerization of thinking and culture, I articulate techniques of information analysis as research method in the humanities. The challenge today is in producing knowledge that is analytically rigorous, durable, and independent from various securitized and militarized power centers and policy circles. What are the new forms of sociality and political action enabled by global networks? How does one consider the multiplicities of networks: solidarity networks, artistic networks, academic networks, virtual networks; networked images as political instruments; and media of global political action since the Arab Spring; the new body politic as a body without skin? 


\section{References}

Agamben, G. (1998) Homo sacer. Sovereign Power and Bare Life. Stanford, CA: Stanford University Press

Agamben, G. (2005) State of Exception. Chicago: University of Chicago Press

Anderson, C. (2008) 'The End of Theory: The Data Deluge Makes the Scientific Method Obsolete', Wired, June 23

Benjamin, W. (2008) The Work of Art in the Age of Mechanical Reproduction. New York: Penguin Books

Hanafi, S. (2012) 'The Arab revolutions; the emergence of a new political subjectivity', Contemporary Arab Affairs, 5:2, 198-213

Hayles, N. K. (1999) How We Became Posthuman: Virtual Bodies in Cybernetics, Literature, and Informatics. Chicago: $U$ of Chicago Press

Hayles, N. K. (2003) 'Translating Media: Why We Should Rethink Textuality', Yale Journal of Criticism, vol. 6, no. 3, 263-290

Hedges, Chris. (2015) "Pornography Is What the End of the World Looks Like," OpEdNews, February 15: http://www.opednews.com/articles/Pornography-lsWhat-the-E-by-Chris-Hedges-Culture INDUSTRY Internet Pornography$\underline{150215-176 . h t m l}$

Kierkegaard, S. (1962) The Present Age. New York: Harper and Row

LeVine, M. (2012) 'Music and the Aura of Revolution', International Journal of Middle East Studies. Vol. 44, 04, 794-797. DOI 10.1017/S002074381200092X

Laila Shereen Sakr is a digital media theorist and artist known by her moniker, VJ Um Amel, and for creating the archive media system, R-Shief. Her PhD in Media Arts + Practice from USC's School of Cinematic Arts will confer in May 2015. She begins her appointment as Assistant Professor in the Department of Film and Media Studies at UC Santa Barbara in July 2015.

Her website is http://vjumamel.com 